\title{
Effects of a GSK-3ß inhibitor on the renal expression levels of RANK, RANKL and NF-кB in a rat model of diabetic nephropathy
}

\author{
YI-XIA ZHOU ${ }^{1,2}$, LI-XIN SHI ${ }^{1}$, HUA YANG $^{1}$, YI-GUO LONG ${ }^{1}$, LU MENG $^{2}$, \\ LI-SA LV ${ }^{2}$, YANG ZHANG ${ }^{2}$, HUAN YAO ${ }^{2}$, LONG LI ${ }^{1}$ and YAN-NI YU ${ }^{2}$ \\ ${ }^{1}$ Nursing Department, Affiliated Hospital of Guizhou Medical University; ${ }^{2}$ Department of Pathology, \\ Guizhou Medical University, Guiyang, Guizhou 550004, P.R. China
}

Received November 24, 2014; Accepted November 25, 2015

DOI: $10.3892 /$ etm.2016.3184

\begin{abstract}
The present study aimed to investigate the effects

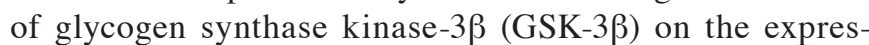
sion levels of receptor activator of nuclear factor $(N F)-\kappa B$ (RANK), RANK ligand (RANKL) and NF- $\kappa$ B in the renal tissues of rats modeling diabetic nephropathy (DN). The rats were allocated at random into three groups, as follows: Normal control group (NC), the DN model group (DNM group) and the DN model lithium chloride ( $\mathrm{LiCl}$ ) intervention group (DNI group). Urinary proteins were examined by staining with the Coomassie Brilliant Blue dye for $24 \mathrm{~h}$. Histochemical analyses of kidney tissue sections were conducted using hematoxylin and eosin staining, after which the kidney pathology of the rats was observed. In addition, the mRNA and protein expression levels of GSK-3 $\beta$, RANK, RANKL and NF- $\kappa$ B in the renal tissues were detected using reverse transcription-quantitative polymerase chain reaction and immunohistochemistry, respectively. As compared with the $\mathrm{NC}$ group, the level of urinary protein was significantly increased in the DNM group $(\mathrm{P}<0.05)$; however, as compared with the DNM Group, the level of urinary protein at 12 weeks was significantly decreased in the DNI group $(\mathrm{P}<0.05)$. As compared with the NC group, marked pathological changes were detected, and the mRNA and protein expression levels of GSK-3 $\beta$, RANK, RANKL and $N F-\kappa B$ were significantly increased, in the renal tissues of the DNM group. Conversely, pathological alterations in
\end{abstract}

Correspondence to: Dr Long Li, Nursing Department, Affiliated Hospital of Guizhou Medical University, 28 Guiyi Street, Guiyang, Guizhou 550004, P.R. China

E-mail: yixiazhoucn@163.com

Professor Yan-Ni Yu, Department of Pathology, Guizhou Medical University, 9 Beijing Road, Guiyang, Guizhou 550004, P.R. China E-mail: 184863388@qq.com

Key words: diabetic nephropathy, glycogen synthase kinase-3 $\beta$, receptor activator of nuclear factor- $\kappa \mathrm{B}$, receptor activator of nuclear factor- $\kappa \mathrm{B}$ ligand, nuclear factor- $\mathrm{\kappa B}$, lithium chloride the renal tissues were attenuated, and the mRNA and protein expression levels of GSK-3 $\beta$, RANK, RANKL and NF- $\kappa$ B were significantly decreased $(\mathrm{P}<0.05)$, in the DNI group, as compared with the DNM group. The results of the present

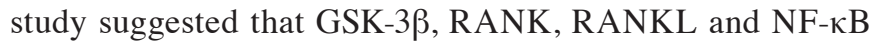
may be crucially involved in the development of DN, and that $\mathrm{LiCl}$ may effectively attenuate $\mathrm{DN}$ by reducing the expression levels of GSK-3 $\beta$, RANK, RANKL and NF- $\kappa$ B.

\section{Introduction}

The incidence of diabetes mellitus (DM) has increased year upon year. Diabetic nephropathy (DN) is the most common serious microvascular complication associated with DM, and is the predominant cause of end-stage renal disease and mortality $(1,2)$. However, the underlying pathogenesis of DN is complex $(3,4)$, and has yet to be fully elucidated, although previous studies have associated genetic factors, glucose metabolism, hemodynamic alterations, oxidative stress and cell and inflammatory factors with its occurrence and development $(5,6)$. DN has been shown to be a type of inflammatory process, and thus various anti-inflammatory therapies have been used for its treatment (7). In a previous study, glycogen synthase kinase-3 $\beta$ (GSK-3 $\beta$ ) exerted regulatory effects on inflammation via the tumor necrosis factor- $\alpha$-induced nuclear factor $(N F)-\kappa B$ signaling pathway (8); thus suggesting that the NF- $\kappa$ B signaling pathway may be involved in DN. Previous studies reported that the receptor activator of NF- $\mathrm{KB}$ (RANK) and its ligand (RANKL) have a key role in the differentiation, development and maturation of osteoclast cells (9-11). In addition, RANK and RANKL have been implicated in the pathogenesis of various diseases, including autoimmune thyroiditis, Crohn's disease and rheumatoid arthritis $(12,13)$. Previous studies have reported that rat models of glomerulosclerosis with 5/6 nephrectomy and podocyte injury caused by puromycin amino exhibited elevated expression levels of RANK and RANKL $(14,15)$. However, to the best of our knowledge, the underlying mechanism by which GSK-3 $\beta$ may regulate the NF- $\kappa \mathrm{B}$ signaling pathway in DN has yet to be investigated. The characteristic lesions of DN have also been associated with podocyte injury (16). Therefore, the present study aimed to investigate the effects and associations of 
GSK-3 $\beta$, RANK, RANKL and NF- $\mathrm{B}$ in a rat model of DN. In addition, lithium chloride $(\mathrm{LiCl})$ treatment was used to inhibit GSK-3 $\beta$, and alterations in the mRNA and protein expression levels of RANK, RANKL and NF- $\kappa B$ were detected in the renal tissues of the rats, in order to devise novel strategies for the treatment of DN.

\section{Materials and methods}

Establishment of an animal model of DN and grouping. A total of 24 healthy Sprague-Dawley rats (age, 8 weeks; weight, 200-250 g), including 12 female and 12 male rats, from the Laboratory Animal Center at the Guizhou Medical University (Guiyang, China), were fed a normal diet for 2 weeks, after which tail vein blood glucose concentrations were measured. A total of 8 rats were randomly selected to form the normal control (NC) group. Diabetes was induced in the remaining 16 rats by intraperitoneal injection with $55 \mathrm{mg} / \mathrm{kg}$ streptozotocin solution (Sigma-Aldrich, St. Louis, MO, USA) following fasting. The rats in the $\mathrm{NC}$ group were injected with an identical volume of solvent (citric acid-sodium citrate buffer). Venous blood was collected after $72 \mathrm{~h}$, and a glucose concentration of $>16.7 \mathrm{mmol} / \mathrm{l}$ was as an indicator of diabetes (17). The two groups were fed for 10 weeks, during which the rats were weighed and the blood glucose levels were measured weekly. After 10 weeks, the rats were fasted, receiving only water, for $24 \mathrm{~h}$. Next the rats underwent measurement of urine protein concentration; a protein concentration of $\geq 30 \mathrm{mg}$ or $>10$-times that of the NC group was considered to indicate DN in the diabetic rats (18). The 16 rats in the successfully established DN group were randomly divided into the DN model (DNM) group and the DN model lithium chloride $(\mathrm{LiCl})$ intervention $(\mathrm{DNI})$ group $(\mathrm{n}=8$ rats per group). The DNI group was injected with $15 \mathrm{mg} / \mathrm{kg} \mathrm{LiCl}$ (Sigma-Aldrich) for 10 days, whereas the DNM and NC groups received an equal volume of saline. At 1 day prior to sacrifice, the urine samples were collected over $24 \mathrm{~h}$, after which the rats were anaesthetized by abdominal injection with $0.2 \%$ propofol in medium- and long-chain triglyceride emulsion $(1 \mathrm{ml} / 100 \mathrm{~g}$ body weight; Guangdong Jiabo Pharmaceutical Co., Ltd., Guangzhou, China), followed by sacrifice by cervical dislocation on day 12 . The rat kidneys were harvested, fixed with $10 \%$ neutral buffered formalin, embedded in paraffin and cut into $3-\mu \mathrm{m}$ sections, in order to conduct hematoxylin and eosin (HE) staining (Fuzhou Maixin Biotechnology Development Co., Ltd., Fuzhou, China) and immunohistochemical analyses. The present study was conducted in accordance with the recommendations outlined in the Guide for the Care and Use of Laboratory Animals (National Institutes of Health, Bethesda, MA, USA). The animal use protocol was reviewed and approved by the Institutional Animal Care and Use Committee of the Guizhou Province, China.

Detection of general index. The concentration of urinary protein was determined by Coomassie Blue staining (Sangon Biotech Co., Ltd., Shanghai, China) and the blood glucose was measured using a glucose meter (MHY-26413; Beijing Meihua Instrument Technology Co., Ltd., Beijing, China).

Samples of renal tissues. All rats were anaesthetized by abdominal injection with $0.2 \%$ propofol in medium- and long-chain triglyceride emulsion, prior to sacrifice by cervical dislocation. Subsequently, the kidneys were harvested, the renal capsule was removed, and the kidneys were flushed with saline, fixed and preserved at $4^{\circ} \mathrm{C}$ for HE staining and immunohistochemical analyses. The left kidney was stored in an ice box maintained at $-80^{\circ} \mathrm{C}$ prior to reverse transcription-quantitative polymerase chain reaction (RT-qPCR).

$H E$ staining. Paraffin-embedded 3- $\mu \mathrm{m}$ kidney sections were baked at $55^{\circ} \mathrm{C}$ in the oven for $10 \mathrm{~min}$, dewaxed, and immersed in xylene for $10 \mathrm{~min}$. After removing the xylene, the kidney sections were washed with water and incubated with $1 \%$ hematoxylin solution for $5 \mathrm{~min}$. Subsequently, the tissue sections were washed with tap water and $1 \%$ hydrochloric acid, followed by incubation with $0.5 \%$ eosin stain for $2 \mathrm{~min}$. After rinsing with tap water, the kidney sections were placed in double distilled water, dehydrated and mounted with neutral glue. Alterations in the morphologies of the glomerulus, tubules and interstitium of the renal tissues of the rats were observed in the Q550CW Image Acquisition and Analysis System (Leica Microsystems, GmbH, Wetzlar, Germany).

Immunohistochemistry. Paraffin-embedded kidney sections were baked and dehydrated, followed by washing with phosphate-buffered saline (PBS; Sangon Biotech Co., Ltd.). The sections were repaired for $10 \mathrm{~min}$ using $0.01 \mathrm{M}$ citrate repair solution ( $\mathrm{pH} 6.0$ ), cooled to room temperature, and washed with PBS. Following incubation with 3\% hydrogen peroxide for $20 \mathrm{~min}$ at room temperature, the kidney sections were incubated with the following primary antibodies: Rabbit anti-rat GSK-3 $\beta$ (1:100; BV4582-100), NF-кB (1:200; BV8453-002), RANK (1:200; BV6545-221) and RANKL (1:200; BV9023-300) polyclonal antibodies (all BioVision, Inc., Milpitas, CA, USA), overnight at $4^{\circ} \mathrm{C}$. On the following day, the kidney sections were incubated with peroxidase-conjugated secondary antibodies at $20-37^{\circ} \mathrm{C}$ for $60 \mathrm{~min}$. The antibody complexes were visualized by staining with diaminobenzidine (Sigma-Aldrich), after washing with PBS. The reaction was quenched using distilled water, after which the kidney sections were counterstained with hematoxylin for $2 \mathrm{~min}$ and differentiated by alcohol hydrochloride (Sigma-Aldrich). The sections were dehydrated conventionally using alcohol (Sigma-Aldrich), made transparent with xylene (Sigma-Aldrich) and mounted using neutral gum (Fuzhou Maixin Biotechnology Development Co., Ltd.). Finally, the sections were examined under a DVM6 optical microscope (Leica Microsystems, GmbH).

Analysis of immunohistochemical results. The immunohistochemical results were analyzed using the PHMIAS2008CSVER3.0 Automatic Image Analysis system (Phenix Optical (Guangdong), Co., Ltd., Zhongshan, China). Eight image fields were randomly selected in each tissue section under an optical microscope, after which grayscale images were captured and the tubular/spherical positive immunohistochemical staining was observed. The relative protein expression levels were calculated and analyzed using the BIOMIAS-2001 High-Resolution Image Analysis system (Institute of Image and Graphics, Sichuan University, Chengdu, China). Five non-overlapping fields (magnification, $x 400$ ) were 
A

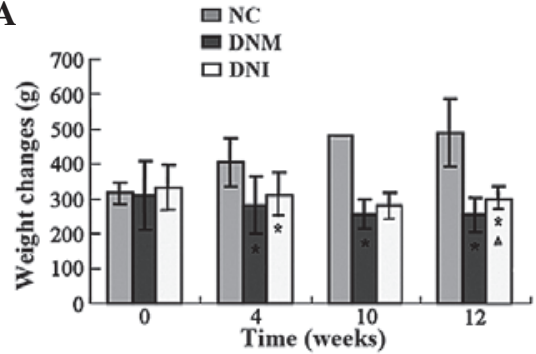

B

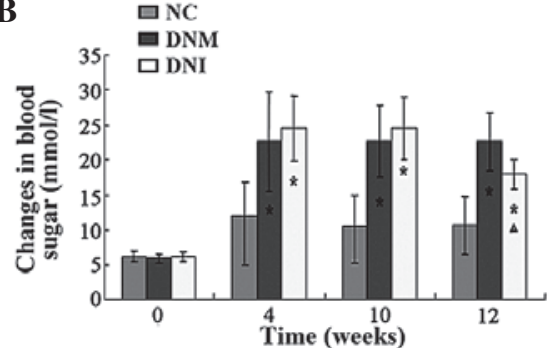

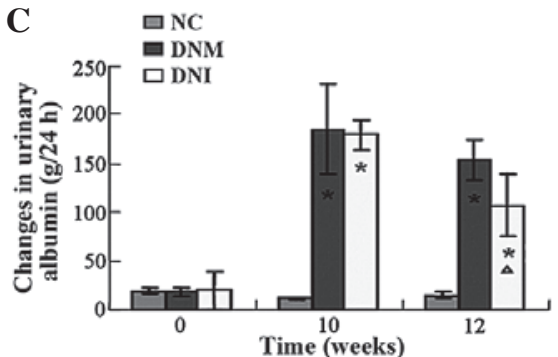

Figure 1 Body weight, blood glucose concentration and urinary albumin levels of the rats in the NC, DNM and DNI groups. Alterations in (A) body weight, (B) blood glucose concentrations, and (C) urinary albumin levels. Data are presented as the mean \pm standard error of the mean. * $<<0.05$ vs. the $\mathrm{NC}$ group; ${ }^{\Delta} \mathrm{P}<0.05$ vs. the DNM group. NC, normal control group; DNM, diabetic nephropathy (DN) model group; DNI, DN model lithium chloride intervention group.
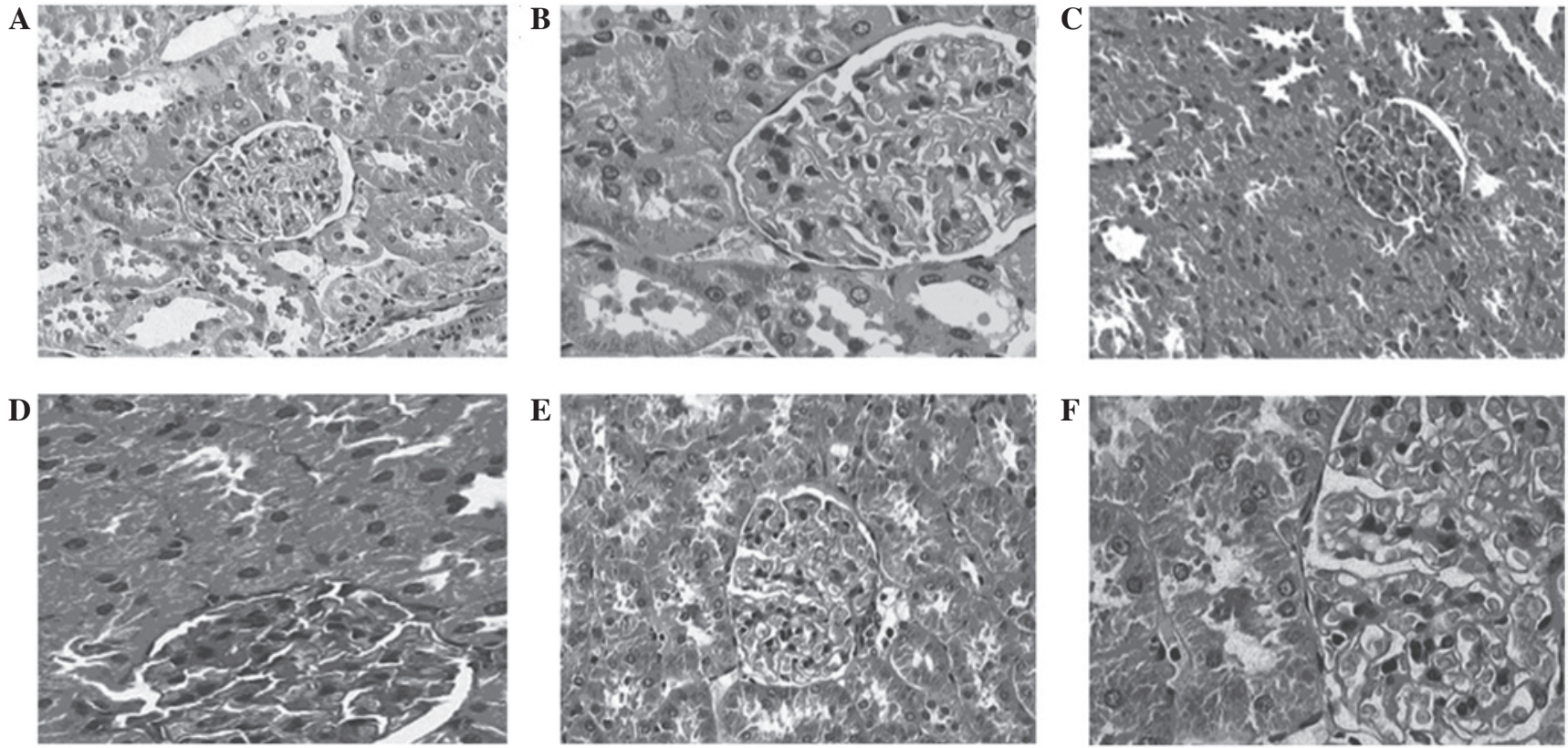

Figure 2. Renal cells of rats in the normal control (NC), diabetic nephropathy (DN) model (DNM) and DN model lithium chloride intervention (DNI) groups. (A) NC group (magnification, x200); (B) NC group (magnification, x400); (C) DNM group (magnification, x200); (D) DNM group (magnification, x400); (E) DNI group (magnification, x200); (F) DNI group (magnification, x400). (A and B) In the NC group, the structure of glomerular appeared normal, the size was uniform, there was no evidence of hypertrophy of endothelial cells, mesangial cells or the glomerular cell wall, the mesangial matrix appeared normal in size and the morphology of the tubules was normal. (C and D) In the DNM group, glomerular hypertrophy was detected, the mesangial matrix was increased in size, the basement membrane was thickened, edema of the epithelial cells of the renal tubules was detected, and the lumen appeared narrowed or occluded. (E and F) In the DNI group, the cells of the mesangial had proliferated, the mesangial matrix was only slightly increased, the basement membrane was thickened only mildly, and edema of tubular epithelial cells was abated.

randomly selected in each section for the determination of integrated optical density (IOD) values for GSK-3 $\beta, N F-\kappa B$, RANK and RANKL. The IOD value was used to represent the expression intensity, where the larger IOD value reflected upregulated expression.

$R T$ - $q P C R$. Total RNA was extracted from the kidney sections using TRIzol ${ }^{\circledR}$ reagent (Invitrogen; Thermo Fisher Scientific, Inc., Waltham, MA, USA) and was treated with RNase-free DNase (Promega Corporation, Madison, WI, USA). The concentration of RNA was quantified using the Nano-200 Nucleic Acid analyzer (Hangzhou Allsheng Instruments Co., Ltd., Hangzhou, China). The reverse transcription reaction with $13 \mu 1$ total RNA was performed using the PrimeScript First Strand cDNA Synthesis kit (Takara Biotechnology Co., Ltd., Dalian, China), according to the manufacturer's protocol.
PCR was conducted using the CFX96 Touch Real-Time PCR Detection System (Bio-Rad Laboratories, Inc., Hercules, CA, USA), with a reaction mixture consisting of $5 \mu \mathrm{l} \mathrm{SYBR}$ Green 1 dye (Thermo Fisher Scientific Inc.), $7.5 \mu 1$ 2X Premix Ex Taq (Sangon Biotech Co., Ltd.), $0.25 \mu 1$ forward and reverse primer,

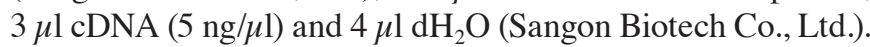
The primers used in the were as follows: GSK-3 $\beta$ forward, 5'-GCTTCAACCCCTTCAAATGC-3' and reverse, 5'-GAC GCAGAAGCGGTGTTATTG-3'; RANK forward, 5'-TTA AGCCAGTGCTTCACGGG-3' and reverse, ACGTAGACC ACGATGATGTCGC-3'; RANKL forward, 5'-GCTCACCTC ACCATCAATGCT-3' and reverse, 5'-GGTACCAAGAGG ACAGACTGACTTTA-3'; NF-кB forward, 5'-ATAGAAGAG CAGCGTGGGGACT-3' and reverse, 5'-GGATGACGTAAA GGGATAGGGC-3'; and $\beta$-actin forward, 5'-GGAGATTAC TGCCCTGGCTCCTA-3', and reverse, 5'-GACTCATCGTAC 

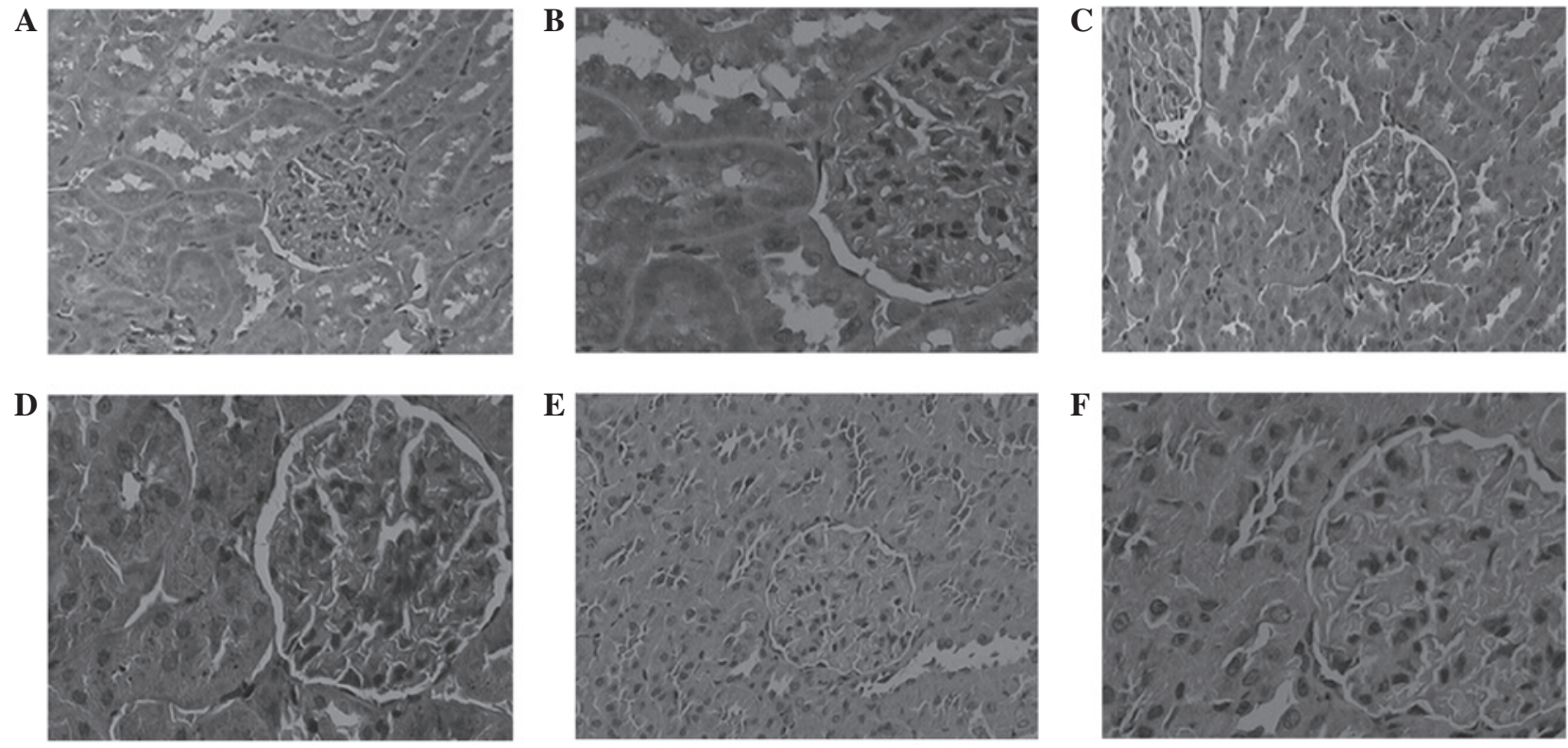

Figure 3. Immunohistochemical analysis of glycogen synthase kinase-3 $\beta$ in the renal tissues of rats in the (A) normal control (NC) group (magnification, x200), (B) NC group (magnification, x400), (C) diabetes nephropathy model (DNM) group (magnification, x200), (D) DNM group (magnification, x400), (E) diabetic nephropathy group treated with lithium chloride (DNI) group (magnification, x200) and (F) DNI group (magnification, $\mathrm{x} 400$ ).

TCCTGCTTGCTG-3' (Generay Biotech, Co., Ltd., Shanghai, China). The PCR cycling conditions were as follows: $95^{\circ} \mathrm{C}$ for $15 \mathrm{~min}$, followed by 40 cycles of $95^{\circ} \mathrm{C}$ for $15 \mathrm{sec}, 93^{\circ} \mathrm{C}$ for $30 \mathrm{sec}$ and $55^{\circ} \mathrm{C}$ for $40 \mathrm{sec}$, and a final extension step at $72^{\circ} \mathrm{C}$ for $5 \mathrm{~min}$.

Analysis of RT-qPCR results. The StepOnePlus Real-Time PCR system (Thermo Fisher Scientific, Inc.) was used to amplify the fluorescence signal from each cycle, which was analyzed using the Applied Biosystems Sequence Detection Systems software, version 14.0 (Thermo Fisher Scientific, Inc.). The quantification cycle (CQ) and relative quantification (RQ) values were analyzed as follows: $R Q=2-C Q$. The mRNA expression levels of GSK-3 $\beta$, RANK, RANKL, and $N F-\kappa B$, relative to $\beta$-actin, were calculated using the $2^{-\Delta \Delta C q}$ method (19).

Statistical analysis. Data are presented as the mean \pm standard error of the mean of $\geq 3$ independent experiments. Statistical analyses were conducted using Microsoft Excel with unpaired Student's t-test. $\mathrm{P}<0.05$ was considered to indicate a statistically significant difference.

\section{Results}

General data. Prior to the establishment of the DN model, all rats received standard diets, and had normal faeces and urine. All rats had clean fur, and there was no significant difference in the body weight of the rats between the groups $(\mathrm{P}>0.05$; Fig. 1A). After modeling, the rats exhibited varying degrees of polyuria, polydipsia, polyphagia, weight loss and reduced movement. In addition, the fur of the rats in the DNM and DNI groups was messy and dull in appearance. At 4 and 10 weeks post-modeling, the body weights of the rats in the DNM and DNI groups were significantly reduced, as compared with the body weights of the rats in the NC group $(\mathrm{P}<0.05$; Fig. 1A).

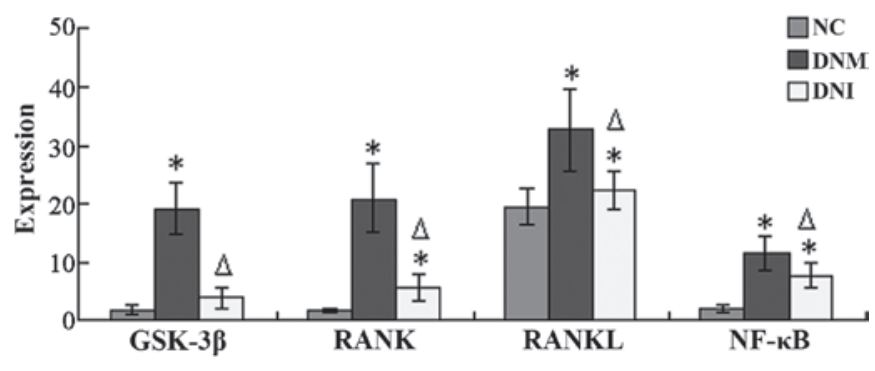

Figure 4. Protein expression levels of GSK-3 $\beta$, RANK, RANKL and NF- $к B$ in the renal cells of rats in the NC, DNM and DNI groups. Data are presented as the mean \pm standard error of the mean. ${ }^{*} \mathrm{P}<0.05$ vs. the $\mathrm{NC}$ group; ${ }^{ } \mathrm{P}<0.05$ vs. the DNM group. GSK-3 $\beta$, glycogen synthase kinase-3 $\beta$; RANK, receptor activator of nuclear factor (NF)-kB; RANKL, RANK ligand; NC, normal control group; DNM, diabetic nephropathy model group; DNI, diabetic nephropathy model group treated with GSK-3 $\beta$ inhibitor group.

At 12 weeks, the body weights of the rats in the DNM and DNI groups were significantly lower, as compared with the $\mathrm{NC}$ group $(\mathrm{P}<0.05$; Fig. $1 \mathrm{~A})$; however, the body weights of the rats in the DNI group were significantly higher, as compared with the DNM group $(\mathrm{P}<0.05$; Fig. 1A). The indices of blood glucose and urine protein concentrations in the DNM and DNI groups were significantly higher, as compared with those of the $\mathrm{NC}$ group $(\mathrm{P}<0.05$; Fig. 1B and $\mathrm{C})$; however, treatment with $\mathrm{LiCl}$ was able to significantly reduce the blood glucose and urine protein concentrations in the DNI rats, as compared with the DNM group $(\mathrm{P}<0.05$; Fig. $1 \mathrm{~B}$ and $\mathrm{C})$. These results suggested that the rat model of DN had been successfully established, and that $\mathrm{LiCl}$ treatment was able to mitigate the $\mathrm{DN}$ in rats.

$H E$ staining. In the NC group, the sizes of the glomeruli appeared uniform, cell proliferation was not detected, the capillary basement membrane was uniform and thin, the mesangium appeared narrow and the cavity of the capillary 

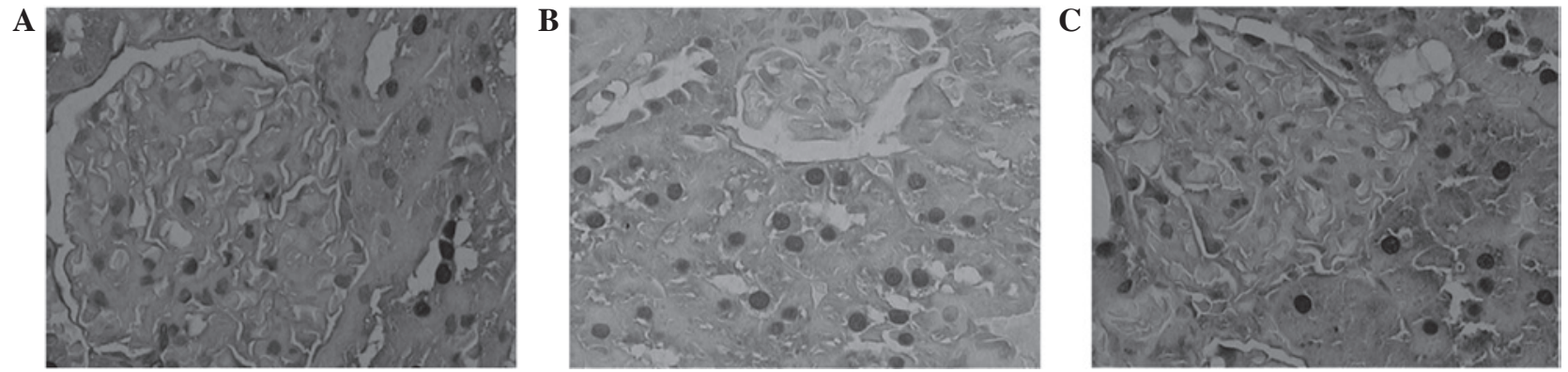

Figure 5. Immunohistochemical analysis of receptor activator of nuclear factor- $\kappa \mathrm{B}$ protein expression levels in the renal cells of rats in the (A) normal control group, (B) diabetic nephropathy model group and (C) diabetic nephropathy group treated with lithium chloride group (magnification, $\mathrm{x} 400$ ).
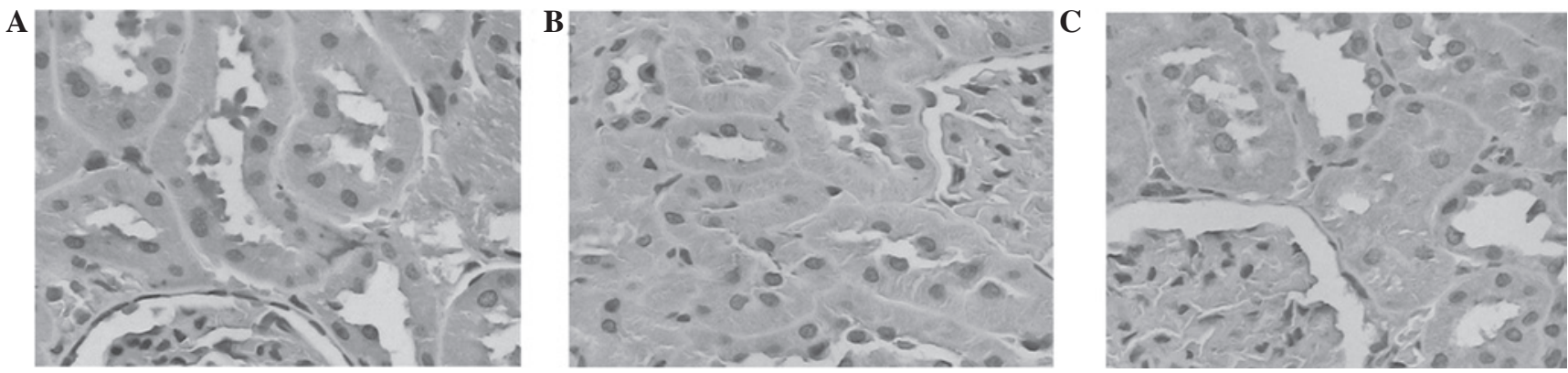

Figure 6. Immunohistochemical analysis of receptor activator of nuclear factor- $\mathrm{kB}$ ligand protein expression levels in the renal cells of rats in the (A) normal control group, (B) diabetic nephropathy group, and (C) diabetic nephropathy group treated with lithium chloride group (magnification, $\mathrm{x} 400$ ).
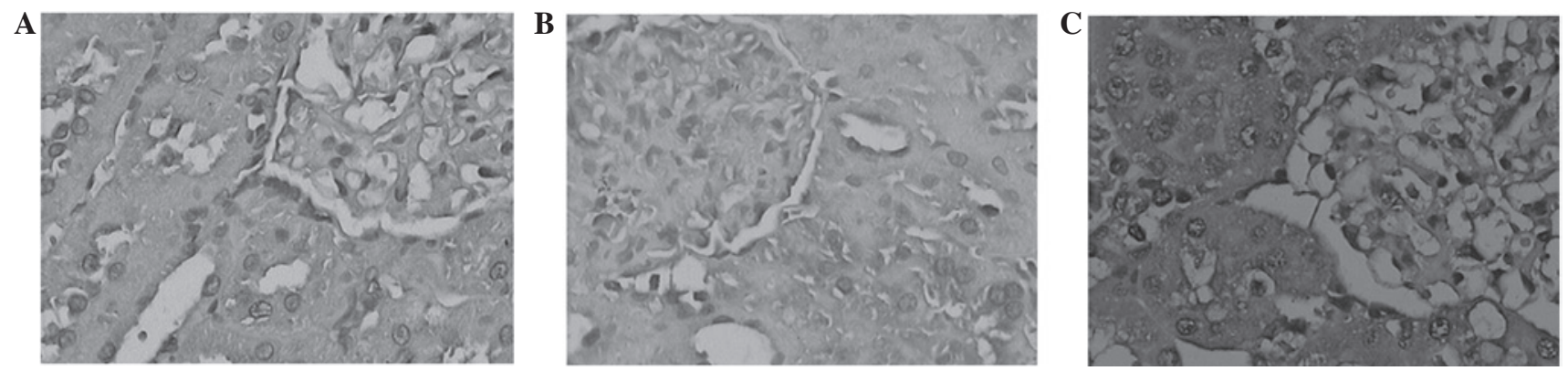

Figure 7. Immunohistochemical analysis of nuclear factor- $\mathrm{kB}$ in the renal tissues of rats in the (A) normal control group, (B) diabetic nephropathy group, and (C) diabetic nephropathy group treated with lithium chloride group (magnification, $\mathrm{x} 400$ ).

was open (Fig. 2A and B). Furthermore, the epithelial cells of the renal tubules were intact, the basement membrane was thin, the peritubular capillaries exhibited no fibrosis and there was no obvious interstitial edema (Fig. 2A and B). Conversely, in the DNM group, the rats exhibited glomerular hypertrophy, the mesangial matrix was increased in size, the capillary basement membrane was thickened and luminal occlusion and renal arteriosclerosis was detected (Fig. 2C and D). In addition, the tubular basement membrane appeared thickened, and stenosis and occlusion, interstitial edema and fibrosis were detected (Fig. 2C and D). In the DNI group, the volume of the glomeruli was slightly increased, and the capillary basement membrane was only marginally thickened, as compared with the DNM group (Fig. 2E and F). In addition, the mesangial matrix was only slightly thickened, the degree of degeneration of tubular epithelial cells was improved, and luminal narrowing was not obvious, as compared with the DNM group (Fig. 2C and D).
Immunohistochemistry. The sites that stained positively for GSK-3 $\beta$ were predominantly in the cytoplasm of renal tubular epithelial cells, although its expression was also detected in the glomeruli. The protein expression levels of GSK-3 $\beta$ were markedly increased in the renal tubular epithelial cells of the DNM group, as compared with the NC group (Fig. 3), and this difference was shown to be significant $(\mathrm{P}<0.05$; Fig. 4). Conversely, the expression levels of GSK-3 $\beta$ were markedly decreased in the DNI group, as compared with the DNM group (Fig. 3), and this difference was shown to be significant $(\mathrm{P}<0.05$; Fig. 4). These results suggested that $\mathrm{LiCl}$ may attenuate $\mathrm{DN}$-induced increases in the expression levels of GSK-3 $\beta$.

Positive sites of RANK protein expression were detected in the glomeruli and certain tubules. The protein expression levels of RANK were markedly increased in the DNM group, as compared with the NC group (Fig. 5), and this difference was shown to be significant $(\mathrm{P}<0.05$; Fig. 4$)$. However, the protein expression levels of RANK were markedly decreased 


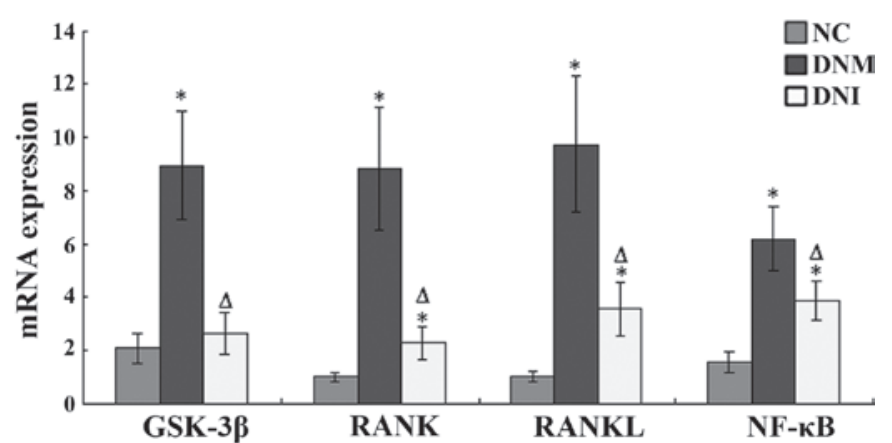

Figure 8. mRNA expression levels of GSK-3 $\beta$, RANK, RANKL and NF- $\kappa$ B in the renal tissues of rats in the NC, DNM and DNI groups. Data are presented as the mean \pm standard error of the mean. ${ }^{*} \mathrm{P}<0.05$ vs. the NC group; ${ }^{\Delta} \mathrm{P}<0.05$ vs. the DNM group. GSK-3 $\beta$, glycogen synthase kinase-3 $\beta$; RANK, receptor activator of nuclear factor (NF)- $\mathrm{B}$; RANKL, RANK ligand; NC, normal control group; DNM, diabetic nephropathy model group; DNI, diabetic nephropathy model group treated with GSK-3 $\beta$ inhibitor group.

in the DNI group, as compared with the DNM group (Fig. 5), and this difference was shown to be significant $(\mathrm{P}<0.05$; Fig. 4).

The RANKL protein was detected in the tubules and glomeruli, and appeared as yellow granules. The protein expression levels of RANKL were markedly increased in the DNM group, as compared with the NC group (Fig. 6), and this difference was shown to be significant $(\mathrm{P}<0.05$; Fig. 4). Conversely, the protein expression levels of RANKL were markedly decreased in the DNI group, as compared with the DNM group (Fig. 6), and this difference was shown to be significant $(\mathrm{P}<0.05$; Fig. 4).

Positive sites of NF- $\kappa \mathrm{B}$ occurred predominantly in the cytoplasm and nucleus of the renal tubules. In the $\mathrm{NC}$ group, low levels of $\mathrm{NF}-\kappa \mathrm{B}$ protein expression were detected in the cytoplasm of tubular epithelial cells only, whereas, in the DNM group, high levels of NF- $\mathrm{BB}$ were detected in the cytoplasm and low levels were detected in the nucleus (Fig. 7). As compared with the same period in the $\mathrm{NC}$ group, the protein expression levels of $\mathrm{NF}-\kappa \mathrm{B}$ were significantly increased in the DNM group ( $\mathrm{P}<0.05$; Fig. 4). Conversely, the protein expression levels of $\mathrm{NF}-\kappa \mathrm{B}$ were markedly decreased in the DNI group, as compared with the DNM group (Fig. 7), and this difference was shown to be significant ( $\mathrm{P}<0.05$; Fig. 4).

$R T$ - $q P C R$. The mRNA expression levels of GSK-3 $\beta$ in the renal tissue sections from the DNM rats were significantly increased, as compared with the $\mathrm{NC}$ rats $(\mathrm{P}<0.05$; Fig. 8), whereas the mRNA expression levels of GSK-3 $\beta$ in the DNI rats were significantly reduced, as compared with the DNM rats $(\mathrm{P}<0.05$; Fig. 8$)$.

The mRNA expression levels of RANK in the renal tissue sections from the DNM and DNI groups were significantly increased, as compared with the $\mathrm{NC}$ rats $(\mathrm{P}<0.05$; Fig. 8). However, the mRNA expression levels of RANK were significantly lower in the DNI group, as compared with the DNM group $(\mathrm{P}<0.05$; Fig. 8).

The mRNA expression levels of RANKL in the renal tissue sections from the DNM and DNI groups were significantly higher, as compared with the NC group ( $\mathrm{P}<0.05$; Fig. 8). However, the mRNA expression levels of RANKL were significantly lower in the DNI group, as compared with the DNM group ( $\mathrm{P}<0.05$; Fig. 8).

The mRNA expression levels of NF- $\kappa \mathrm{B}$ in the renal tissue sections from the DNM and DNI groups were significantly higher, as compared with the NC group $(\mathrm{P}<0.05$; Fig. 8$)$. However, the mRNA expression levels of NF- $\kappa \mathrm{B}$ in the DNI group were significantly lower, as compared with the DNM group $(\mathrm{P}<0.05$; Fig. 8$)$.

\section{Discussion}

DN is a common complication of DM, and a key cause of disability and mortality in patients with DM. The pathogenesis underlying DN is currently unclear, although previous studies have reported multifactorial results, including a disorder of glucose metabolism (20), hemodynamic alterations (21) and inflammatory cytokines (22). GSK-3 $\beta$ is a serine/threonine kinase, which has a variety of functions and exists in all eukaryotic cells (23). Previous studies have demonstrated that, in addition to catalyzing the phosphorylation of glycogen synthase, GSK-3 $\beta$ is involved in signaling pathways, including the insulin (24), Wnt/ $\beta$-catenin (25), Hedgehog (26) and Notch (27) pathways. GSK-3 $\beta$ has also been shown to have a regulatory role in cell differentiation, metabolism, apoptosis and inflammation (28). A positive regulatory role for GSK-3 $\beta$ was initially detected in fibroblasts (29). Subsequently, it was demonstrated that inhibiting the activity of GSK-3 $\beta$ reduced the transcriptional activity of $\mathrm{NF}-\kappa \mathrm{B}$ target genes and the expression of its target proteins (30). NF- $\kappa \mathrm{B}$ is a transcription factor that is expressed by a variety of cells and has been shown to have numerous regulatory roles (31). In the resting state, $N F-\kappa B$ is held in an inactive form in the cytoplasm by its inhibitor $I_{\kappa} B$; however, when a cell encounters one of various stimulators, including oxygen free radicals, cytokines and viruses, I $\mathrm{I} B$ is rapidly degraded, $\mathrm{NF}-\kappa \mathrm{B}$ and $\mathrm{I} \kappa \mathrm{B}$ dissociate and $\mathrm{NF}-\kappa \mathrm{B}$ enters the nucleus and binds to specific sequences, in order to regulate the expression of target genes (32).

In a previous study, stimulation of RANKL was associated with activation of the NF- $\kappa \mathrm{B}$ signaling pathway (33). The signal from RANKL is transduced to TNF receptor-associated factor 6 (TRAF6) via RANK, after which TRAF6 may activate $\mathrm{NF}-\kappa \mathrm{B}$ via the $\mathrm{NF}-\kappa \mathrm{B}$-inducible kinase and the $\mathrm{NF}-\kappa \mathrm{B}$ inducing kinase agent $(34,35)$. In previous studies, RANK expression has not only been in detected in lymphocytes, but also in the precursor cells of osteoclasts, mature osteoclasts and myofibroblasts (35-38).

Inhibitors of GSK-3 $\beta$ have previously been shown to regulate glucose metabolism, the epithelial-mesenchymal transition and insulin resistance, thereby preventing the occurrence of DN (39). Furthermore, previous studies have reported that GSK-3 $\beta$ inhibitors may inhibit the phosphorylation of the $\mathrm{p} 65$ carboxy-terminal, thereby inhibiting the activation of $\mathrm{NF}-\kappa \mathrm{B}$ and reducing the transcription of the ICAM-1 gene $(40,41)$. As an inhibitor of GSK-3 $\beta, \mathrm{LiCl}$ is commonly used for the treatment of mania and various other diseases and its target enzymes include GSK-3 $\beta$ and inositol phosphatase. A previous study demonstrated in vitro and in vivo that GSK- $3 \beta$ regulated the production of various inflammatory mediators by the action of its downstream substrates, including NF- $\mathrm{B}$ and cAMP response element-binding protein, thereby balancing 
pro- and anti-inflammatory responses (42). Therefore, inhibition of GSK-3 $\beta$ may serve a crucial function in the regulation of inflammation (43). Since inflammation is a key factor underlying the pathogenesis of DN (44-46), GSK-3 $\beta$ inhibition may be considered a promising therapeutic target.

The present study aimed to investigate the pathogenesis of DN by detecting the mRNA and protein expression levels of RANK, RANKL and NF- $\kappa$ B in renal tissues from a rat model of DN, as well as analyzing whether treatment of the rats with a GSK-3 $\beta$ inhibitor exerted regulatory effects on the expression levels of RANK, RANKL and NF- $\kappa$ B. The results of the present study suggested that the expression levels of RANK, RANKL and NF- $\kappa$ B were significantly increased in the DNM group, as compared with the NC group; thus suggesting that these proteins may be involved in the development of DN. In addition, $\mathrm{LiCl}$ treatment was able to significantly attenuate the DN-induced increase in the mRNA and protein expression levels of RANK, RANKL and NF- $\kappa$ B. Furthermore, the urine protein concentrations were significantly decreased in the DNI group at $24 \mathrm{~h}$, as compared with the DNM group, and $\mathrm{HE}$ staining demonstrated that $\mathrm{DN}$-induced pathological alterations in the renal tissues of the rats were alleviated in the DNI group.

In conclusion, the present study demonstrated that RANK, RANKL and NF- $\kappa \mathrm{B}$ were involved in the development of $\mathrm{DN}$, and that $\mathrm{LiCl}$ was able to reduce the expression levels of RANK, RANKL and NF- $\kappa$ B by inhibiting GSK-3 $\beta$. In addition, $\mathrm{LiCl}$ treatment attenuated inflammation and endothelial cell apoptosis, which in turn may have delayed the development of DN. These results suggested that GSK-3 $\beta$ may be considered a potential target of cytokines for the treatment of DN.

\section{Acknowledgements}

The present study was supported by the China National Natural Science Foundation (grant no. 31360280), the International Cooperation Projects of Guizhou Province (grant no. [2012]7039), the Qianren Project of Ministry of Human Resources and Social Security of the People's Republic of China (grant no. 2015-04), and the China State Administration of Foreign Experts Affairs Talent Recruitment Project (grant no. 20145200012).

\section{References}

1. Kharroubi AT and Darwish HM: Diabetes mellitus: The epidemic of the century. World J Diabetes 6: 850-867, 2015.

2. Al-Rubeaan K, Youssef AM, Subhani SN, Ahmad NA, Al-Sharqawi AH, Al-Mutlaq HM, David SK and AlNaqeb D: Diabetic nephropathy and its risk factors in a society with a type 2 diabetes epidemic: A Saudi National Diabetes Registry-based study. PLoS One 9: e88956, 2014.

3. Gluhovschi GH, Gluhovschi C, Vlad A, Timar R, Bob F, Velciov S, Bozdog GH and Petrica L: Diabetic nephropathy and multiorgan protection. Part I. Rom J Intern Med 49: $163-177,2011$.

4. Gluhovschi G, Gluhovschi C, Vlad A, Timar R, Bob F, Velciov S, Bozdog G and Petrica L: Diabetic nephropathy and multiorgan protection. Part II. Rom J Intern Med 49: 237-249, 2011.

5. Mooyaart AL, Valk EJ, van Es LA, Bruijn JA, de Heer E, Freedman BI, Dekkers OM and Baelde HJ: Genetic associations in diabetic nephropathy: A meta-analysis. Diabetologia 54: 544-553, 2011
6. Mima A: Inflammation and oxidative stress in diabetic nephropathy: New insights on its inhibition as new therapeutic targets. J Diabetes Res 2013: 248563, 2013.

7. Zhang $X$ and Lu FE: Significance of anti-inflammation and immune regulation in the treatment of diabetic nephropathy. Zhongguo Zhong Xi Yi Jie He Za Zhi 30: 649-654, 2010 (In Chinese).

8. Chang YT, Chen CL, Lin CF, Lu SL, Cheng MH, Kuo CF and Lin YS: Regulatory role of GSK-3 $\beta$ on NF- $\kappa \mathrm{B}$, nitric oxide, and TNF- $\alpha$ in group A streptococcal infection. Mediators Inflamm 2013: 720689, 2013.

9. Tanaka S: Signaling axis in osteoclast biology and therapeutic targeting in the RANKL/RANK/OPG system. Am J Nephrol 27: 466-478, 2007

10. Koya D, Haneda M, Nakagawa H, Isshiki K, Sato H, Maeda S, Sugimoto T, Yasuda H, Kashiwagi A, Ways DK, et al: Amelioration of accelerated diabetic mesangial expansion by treatment with a PKC beta inhibitor in diabetic $\mathrm{db} / \mathrm{db}$ mice, a rodent model for type 2 diabetes. FASEB J 14: 439-447, 2000.

11. Mima A, Ohshiro Y, Kitada M, Matsumoto M, Geraldes P, Li C, Li Q, White GS, Cahill C, Rask-Madsen C and King GL: Glomerular-specific protein kinase $C$ - $\beta$-induced insulin receptor substrate-1 dysfunction and insulin resistance in rat models of diabetes and obesity. Kidney Int 79: 883-896, 2011

12. Ma X, Liu Y, Zhang Y, Yu X, Wang W and Zhao D: Jolkinolide B inhibits RANKL-induced osteoclastogenesis by suppressing the activation NF- $\mathrm{KB}$ and MAPK signaling pathways. Biochem Biophys Res Commun 445: 282-288, 2014.

13. Franchimont N, Reenaers C, Lambert C, Belaiche J, Bours V, Malaise M, Delvenne P and Louis E: Increased expression of receptor activator of NF-kappaB ligand (RANKL), its receptor RANK and its decoy receptor osteoprotegerin in the colon of Crohn's disease patients. Clin Exp Immunol 138: 491-498, 2004.

14. Liu S, Shi W, Xiao H, Liang X, Deng C, Ye Z, Mei P, Wang S, Liu X, Shan Z, et al: Receptor activator of NF-kappaB and podocytes: Towards a function of a novel receptor-ligand pair in the survival response of podocyte injury. PLoS One 7: e41331, 2012.

15. Kelly DJ, Hepper C, Wu LL, Cox AJ and Gilbert RE: Vascular endothelial growth factor expression and glomerular endothelial cell loss in the remnant kidney model. Nephrol Dial Transplant 18: 1286-1292, 2003.

16. Berthier CC, Zhang H, Schin M, Henger A, Nelson RG, Yee B, Boucherot A, Neusser MA, Cohen CD, Carter-Su C, et al: Enhanced expression of Janus kinase-signal transducer and activator of transcription pathway members in human diabetic nephropathy. Diabetes 58: 469-477, 2009.

17. Nam JS, Cheong YS, Karm MH, Ahn HS, Sim JH, Kim JS, Choi SS and Leem JG: Effects of nefopam on streptozotocin-induced diabetic neuropathic pain in rats. Korean J Pain 27: 326-333, 2014.

18. Flyvbjerg A, Denner L, Schrijvers BF, Tilton RG, Mogensen TH, Paludan SR and Rasch R: Long-term renal effects of a neutralizing RAGE antibody in obese type 2 diabetic mice. Diabetes 53: 166-172, 2004

19. Livak KJ and Schmittgen TD: Analysis of relative gene expression data using real-time quantitative PCR and the 2(-Delta Delta C(T)) method. Methods 25: 402-408, 2001.

20. McDonald SD, Pesarchuk E, Don-Wauchope A, El Zimaity H and Holloway AC: Adverse metabolic effects of a hypercaloric, high-fat diet in rodents precede observable changes in body weight. Nutr Res 31: 707-714, 2011.

21. Chirinos JA, Segers P, Gillebert TC, De Buyzere ML, Van Daele CM, Khan ZA, Khawar U, De Bacquer D and Rietzschel ER; Asklepios Investigators: Central pulse pressure and its hemodynamic determinants in middle-aged adults with impaired fasting glucose and diabetes: The Asklepios study. Diabetes Care 36: 2359-2365, 2013.

22. Matia-García I, de la Cruz-Mosso U, Muñoz-Valle JF and Parra-Rojas I: Macrophage migration inhibitory factor and its relationship with obesity and diabetes. Invest Clin 55: 266-277, 2014 (In Spanish).

23. Gong R, Rifai A, Ge Y, Chen S and Dworkin LD: Hepatocyte growth factor suppresses proinflammatory $\mathrm{NF \kappa B}$ activation through GSK3 $\beta$ inactivation in renal tubular epithelial cells. J Biol Chem 283: 7401-7410, 2008.

24. Bouskila M, Hirshman MF, Jensen J, Goodyear LJ and Sakamoto K: Insulin promotes glycogen synthesis in the absence of GSK3 phosphorylation in skeletal muscle. Am J Physiol Endocrinol Metab 294: E28-E35, 2008. 
25. Ho C, Lee PH, Hsu YC, Wang FS, Huang YT and Lin CL: Sustained Wnt $/ \beta$-catenin signaling rescues high glucose induction of transforming growth factor- $\beta 1$-mediated renal fibrosis. Am J Med Sci 344: 374-382, 2012.

26. Ougolkov AV and Billadeau DD: Inhibition of glycogen synthase kinase-3. Methods Mol Biol 468: 67-75, 2008.

27. Kavanagh D, McKay GJ, Patterson CC, McKnight AJ, Maxwell AP and Savage DA; Warren 3/UK GoKinD Study Group: Association analysis of Notch pathway signalling genes in diabetic nephropathy. Diabetologia 54: 334-338, 2011.

28. Holmes T, O'Brien TA, Knight R, Lindeman R, Symonds G and Dolnikov A: The role of glycogen synthase kinase-3beta in normal haematopoiesis, angiogenesis and leukaemia. Curr Med Chem 15: 1493-1499, 2008.

29. Aljada A, Ghanim H, Saadeh R and Dandona P: Insulin inhibits NFkappaB and MCP-1 expression in human aortic endothelial cells. J Clin Endocrinol Metab 86: 450-453, 2001.

30. Chen H, Yang S, Yang Z, Ma L, Jiang D, Mao J, Jiao B and Cai Z: Inhibition of GSK-3beta decreases NF-kappaB-dependent gene expression and impairs the rat liver regeneration. J Cell Biochem 102: 1281-1289, 2007.

31. Baldwin AS Jr: The NF-kappa B and I kappa B proteins: New discoveries and insights. Annu Rev Immunol 14: 649-681, 1996.

32. Perkins ND: Integrating cell-signalling pathways with NF-kappaB and IKK function. Nat Rev Mol Cell Biol 8: 49-62, 2007.

33. Otero JE, Chen T, Zhang K and Abu-Amer Y: Constitutively active canonical NF- $\kappa \mathrm{B}$ pathway induces severe bone loss in mice. PLoS One 7: e38694, 2012.

34. Darnay BG, Ni J, Moore PA and Aggarwal BB: Activation of NF-kappaB by RANK requires tumor necrosis factor receptor-associated factor (TRAF) 6 and NF-kappaB-inducing kinase. Identification of a novel TRAF6 interaction motif. J Biol Chem 274: 7724-7731, 1999.

35. Ruocco MG, Maeda S, Park JM, Lawrence T, Hsu LC, Cao Y, Schett G, Wagner EF and Karin M: I\{kappa\}B kinase (IKK) $\{$ beta\}, but not IKK $\{$ alpha\}, is a critical mediator of osteoclast survival and is required for inflammation-induced bone loss. J Exp Med 201: 1677-1687, 2005.
36. Satomi N, Sakurai A and Haranaka K: Relationship of hypoglycemia to tumor necrosis factor production and antitumor activity: Role of glucose, insulin, and macrophages. J Natl Cancer Inst 74: 1255-1260, 1985.

37. Gilbert RE, Kim SA, Tuttle KR, Bakris GL, Toto RD, McGill JB, Haney DJ, Kelly DJ and Anderson PW: Effect of ruboxistaurin on urinary transforming growth factor-beta in patients with diabetic nephropathy and type 2 diabetes. Diabetes Care 30: 995-996, 2007.

38. Ohshiro Y, Ma RC, Yasuda Y, Hiraoka-Yamamoto J, Clermont AC, Isshiki K, Yagi K, Arikawa E, Kern TS and King GL: Reduction of diabetes-induced oxidative stress, fibrotic cytokine expression, and renal dysfunction in protein kinase Cbeta-null mice. Diabetes 55: 3112-3120, 2006.

39. Gao C, Hölscher C, Liu Y and Li L: GSK3: A key target for the development of novel treatments for type 2 diabetes mellitus and Alzheimer disease. Rev Neurosci 23: 1-11, 2012.

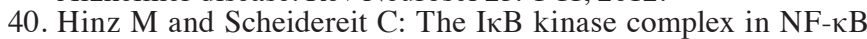
regulation and beyond. EMBO Rep 15: 46-61, 2014

41. Chen Y, Gan H, Ouyang Q, Xu D, Pan Y and A Z: The effects of anti-inflammatory on activation of nuclear factor-kappaB and expression of cell adhesion molecules in patients with ulcerative colitis. Sheng Wu Yi Xue Gong Cheng Xue Za Zhi 21: 732-736, 2004 (In Chinese)

42. Ali A, Hoeflich K and Woodgett JR: Glycogen synthase kinase-3: Properties, functions, and regulation. Chem Rev 101: 2527-2540, 2001.

43. You W, Min X, Zhang X, Qian B, Pang S, Ding Z, Li C, Gao X, Di R, Cheng Y and Liu L: Cardiac-specific expression of heat shock protein 27 attenuated endotoxin-induced cardiac dysfunction and mortality in mice through a PI3K/Akt-dependent mechanism. Shock 32: 108-117, 2009.

44. García-García PM, Getino-Melián MA, Domínguez-Pimentel V and Navarro-González JF: Inflammation in diabetic kidney disease. World J Diabetes 5: 431-443, 2014.

45. Agrawal NK and Kant S: Targeting inflammation in diabetes: Newer therapeutic options. World J Diabetes 5: 697-710, 2014.

46. Duran-Salgado MB and Rubio-Guerra AF: Diabetic nephropathy and inflammation. World J Diabetes 5: 393-398, 2014. 